\title{
大数据时代智慧全域旅游云平台设计分析
}

\author{
何丞刚 方小明 冯庆锋 \\ 杭州快盈信息科技有限公司，浙江 杭州 310052
}

[摘要]文中简要介绍了智慧旅游体系设计理念: 信息资源高效交互、全面采集客流资源、深层挖掘游客需求、构建全域智慧 旅游新环境; 探索了智慧旅游云服务的设计方法: 大数据平台整体设计、景区业务模块设计、智能服务模块设计、景区运维 模块设计等, 以期在旅游各环节中融合智能服务思想, 提升智慧旅游构建的全面性, 为游客提供优质的旅游服务, 增强游客 旅游体验。

[关键词]智能服务; 客流资源；票务处理

DOI: $10.33142 /$ sca.v4i2.3821 中图分类号: TP393.09;F592

文献标识码: A

\section{Design and Analysis of Intelligent Global Tourism Cloud Platform in the Era of Big Data}

\author{
HE Chenggang, FANG Xiaoming, FENG Qingfeng
}

Hangzhou Kuaiying Information Technology Co., Ltd., Hangzhou, Zhejiang, 310052, China

\begin{abstract}
This paper briefly introduces the design concept of smart tourism system: efficient interaction of information resources, comprehensive collection of passenger flow resources, deep mining of tourists' needs, and construction of a new environment for global smart tourism. This paper explores the design methods of smart tourism cloud service: the overall design of big data platform, the business module design of scenic area, the intelligent service module design, the operation and maintenance module design of scenic area, etc., in order to integrate the idea of intelligent service in all aspects of tourism, improve the comprehensiveness of smart tourism construction, provide high-quality tourism services for tourists and enhance the tourism experience of tourists.
\end{abstract}

Keywords: intelligent service; passenger flow resources; ticket handling

\section{引言}

旅游业作为服务综合性、游客与景区各类信息资源大量汇集的产业, 在近年来获得了规模化发展。国内旅游行业 的发展, 在景区资源挖掘、服务多元化的发展进程中, 同样存在诸多运营问题, 比如文化挖掘程度不足、景区秩序不 佳、政府规划效果不到位、景区基建配置不全面等, 成为旅游行业发展的障碍。因此, 在新时期, 以大数据技术为视 角, 构建智能旅游体系, 发挥云平台服务作用, 极具研究价值。

\section{1 智慧旅游体系设计理念}

\section{1 信息资源高效交互}

1.1 .1 智慧旅游体系规划

在云平台作用下, 能够提升旅游产业各类资源的整合效果，包括旅游资讯、产品信息、景区样貌、服务项目等, 形成旅游信息的集中平台, 确定了旅游程序中任意元素的功能角色, 以期组建成智慧旅游系统。在云平台中, 旅游信 息数据作为信息传输的媒介, 能够将各类单一、未整合的分支程序有序集成, 尝试在数据感知作用下, 有效关联景区 内的各项功能模块, 比如娱乐、餐饮、购物广场、交通运输等, 保障景区各环节中信息交流的有序性, 作为智慧旅游 平台构建的关键思想 ${ }^{[1]}$ 。

\section{1 .2 智慧旅游体系规划实例}

比如, $\mathrm{A}$ 单位开发的智慧旅游平台, 完成了 “吃、住、行、游、购、娱” 多项资源整合, 增强了景区智能服务层次、 各项目营销能力，有效提升游客景区游玩体验。项目功能如下:

(1) 支持支付宝、微信双向在线支付，以小程序形式向游客展现景区服务功能。

(2) Web 集中式游客管理模式。

(3) 系统功能涵盖票务、酒店等项目, 为游客提供信息查询、服务预订等操作界面, 便于游客制定游玩攻略、预 览导游规划、咨询景区服务, 以增强游客智慧旅游体验。 


\section{2 全面采集客流资源}

借助景区内的各类监控设备, 比如视频监控、影像传感等, 开展全景信息智慧采集, 以此获取较为全面的客流资 源, 比如单位时间内的客流量、游客在景区的安全情况、来访游客的整体特征、游客在景区的消费倾向等。与此同时, 在客流资源全面采集的基础上，能够进行客流资源有效划分与控制，开展精准旅游营销工作，合理保障景区内的安全 性，为景区资源深层开发、功能完善提供决策依据。

例如, A 单位开发的智慧旅游平台, 在应用层中, 进行了景区各业务集中处理, 分别从在线支付、票务管理等视角, 以面向对象为程序设计视角, 同时具备旅游身份验证、景区监控、流量控制等功能, 为景区游客资源获取奠定了坚实 基础。

\section{3 深层挖掘游客需求}

旅游服务单位, 借助官方网站的服务形式, 采取公众号、小程序等方式, 与游客形成线上互动, 尝试为游客提供 多元化景区服务。在线上互动支持下, 能够增加景区与游客交流次数, 在交流中形成了客户景区消费需求, 为智慧旅 游数据深层挖掘奠定了基础条件。在旅游服务分支程序中，应加强游客数据信息采集，同时开展有效的分析与预测。 比如, 针对游客流量、交通状况等情况, 设计合理的管控方式, 保障景区运作秩序的同时, 增强游客景区游玩体验。

\section{4 构建全域智慧旅游新环境}

在智慧旅游程序构建设计期间, 针对具有差异性表现的数据信息, 应采取区别的处理方式, 同时将处理完成的数 据进行集中反馈, 以期为游客提供更多精准的产品服务, 提升智慧旅游服务品质。在智能服务、精准信息推送的多重 作用下, 尝试为游客构建全域智慧旅游新环境, 最大化减少智慧服务盲区, 分别从景区观光、商务活动、城市度假、 乡村采摘、文化宣传、文娱项目等视角，全面规划旅游模式，以期高效整合旅游资源，增强智慧旅游发展能效。

\section{2 智慧旅游云服务的设计方法}

\section{1 大数据平台整体设计}

在信息环境中，大数据的特点包括：处理量大、传输高速、数据类型多样化、数据价值潜在性等。在大数据技术 作用下, 能够提升数据量的处理级别, 切实深层获取数据潜在价值。同时, 在云计算环境中, 能够集成处理各类数据, 为大数据挖掘技术提供充足可分析的数据, 保障数据处理高效性。因此, 借助大数据技术, 充分发挥其数据分析能力, 助力智慧旅游平台运行。

平台整体设计：云服务中心含有两个程序，分别为线上咨询、线下交流，平台设计以线上模块为主。

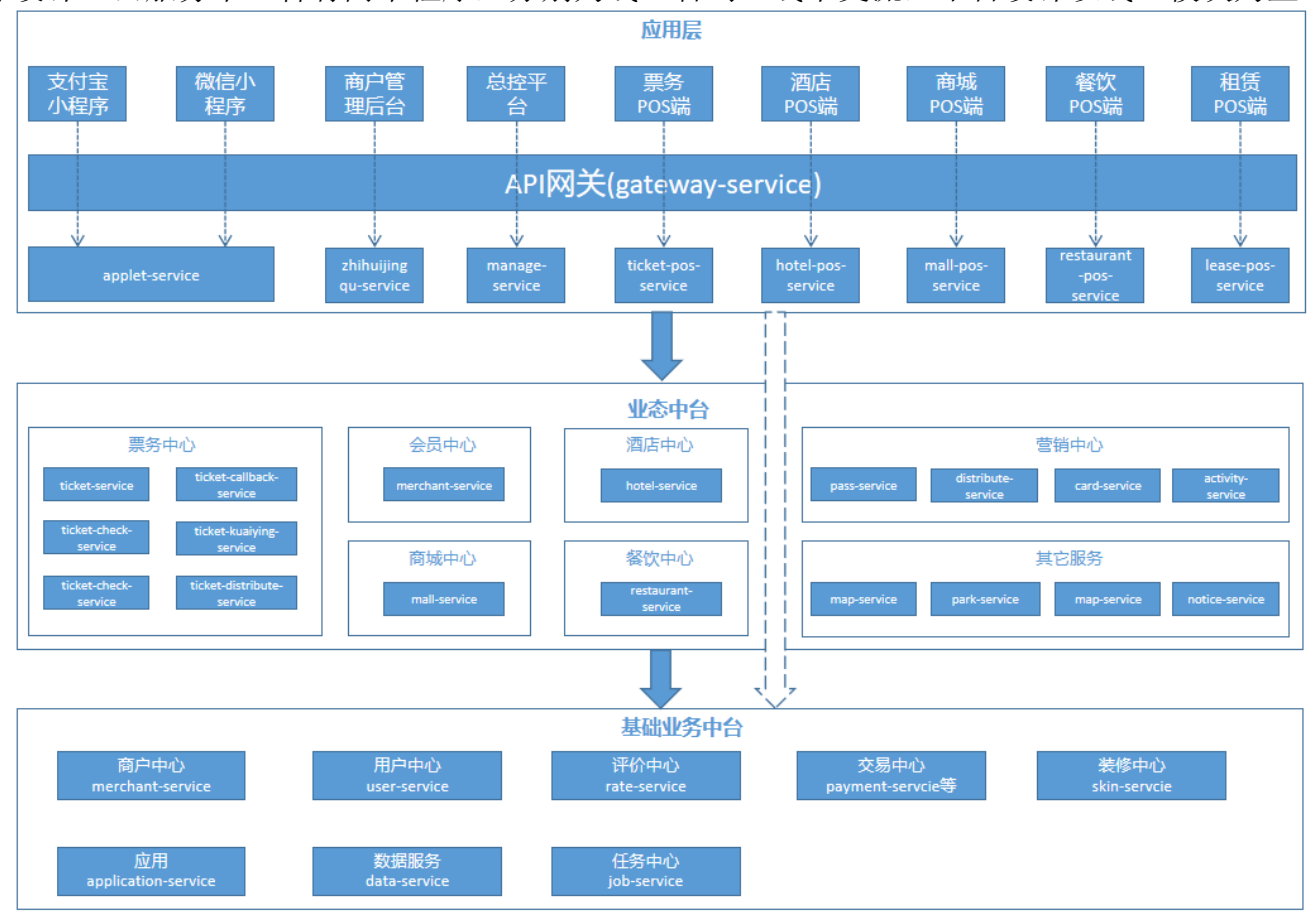

图 $1 \quad A$ 单位项目开发系统框架图 
如图 1 所示, 为 $\mathrm{A}$ 单位项目开发系统框架图。

2.1 .1 线上平台设计

在线上咨询程序中, 引入了云服务集成数据, 尝试以智能客服、人工客服等方式, 为游客提供线上服务; 线上平 台构建时, 涵盖景区全范围的核心业务, 比如业务、景点推荐、智能服务、数据分析等; 同时线上服务体系中, 增设 了功能可扩展的接口, 保障系统开发空间的充足性。在线上全范围业务覆盖的情况下, 能够保障景区资源、智能平台 的集中管理效果。

\section{1 .2 线下平台设计}

线下交流程序中, 采取了景区业务资源整合、程序高效集成等处理方式, 尝试构建线下智能服务操作终端, 分别 从监控、调度、服务等视角, 完成线下资源交互、提升游客景区服务体系的运作能效 ${ }^{[2]}$ 。

2.1.3 平台框架

（1）智能服务层, 以智慧客服、人工客服两个程序为主。在智慧客服中, 针对景区内简单问题, 进行智能回复。 人工客服集中处理较复杂的咨询问题。

（2）应用层。一智慧管理项目: 完成平台应用管理; 开展数据决策; 数据分析; 针对景区内的突发事故, 开展应 急处理工作; 景区人资管理。二智慧服务项目: 景区信息的全面投放; 景区活动的动态化发布; 游客行程个性化设计; 旅游问题咨询。三智慧营销项目：电子票务、综合票务等。四智慧防护项目：智能防护、安全预警等。

(3) 数据处理层: 一数据处理功能有: 数据高效采集、数据准确处理、数据按类存储、数据精准分析。二数据库 类型包括: 旅游服务单位、景区资源、旅游产品等。

（4）智能技术层: 大数据深层挖掘技术、关键词索引技术、人工智能服务、定位地图。

\section{2 景区业务模块设计}

（1）云数据: 借助各类智能技术, 比如云计算、物联网等, 全面整合景区内的各类数据, 比如娱乐餐饮、购物娱 乐等, 构建顺应景区发展的数据体系。

(2) 大数据: 云平台中含有多个数据体系, 在数据管理作用下, 能够提升数据平台功能服务的完整性, 数据平台 中含有多种类型的数据库, 表现为数据分析、智能学习、数据管理等功能, 尝试为云计算高效运行助力。

(3) 物联网程序: 采取可视化设计方式, 智能处理较大量的数据, 发挥物联网数据程序的服务功能, 提升程序计 算效率。

（4）资源集成平台; 作为景区内各环节的资源集成中心，尝试为游客、景区管理提供资源服务。游客在平台中, 能够完成线上支付, 提升旅游智能管理标准性。景区管理在此平台中, 能够借助可视化传感信息、地理定位程序, 合 理规划景区资源。

\section{3 智能服务模块设计}

(1) 客流监控统计。借助多个智能终端, 尝试动态化掌握景区客流数据, 针对特定景区, 开展有效的客流测评工 作。如若游客数量达到了景区人流兼容的最大值, 可对后续来访游客采取分流措施, 以此减少景区客流拥堵问题, 保 障景区运营的有序性, 维护游客观赏体验。

（2）游客属性确定。在数据挖掘程序中, 有效采集游客各类信息, 确定游客属性类别, 挖掘客户潜在需求, 以期 为游客提供精准服务 ${ }^{[3]}$ 。比如, 采取智能标签形式, 记录游客的消费倾向、个人喜好等信息, 形成用户特征模型, 对其 开展精准营销, 顺应游客潜在消费需求。

\section{4 景区运维模块设计}

运维模块设计, 包括景区故障问题、安全问题的检测与处理, 采取巡检装置, 及时记录景区内各类设施的整体情 况, 分别从照明、交通设施等视角, 开展运维管理, 保障设施品质, 提升检修效率。在智能运维体系中, 能够精准判 断故障位置, 以缩短检修时间, 保障景区运维的智能性。

\section{5 智能票务处理程序设计}

(1) 订单管理程序。此程序与旅游产品平台相互关联, 结合订单情况, 准确核实产品价位, 以高效完成订单处理, 比如售票、验票等。

（2）旅游产品信息宣传。此程序为游客提供信息服务，提供门票、团体票等价位信息。 
（3）会员管理。采取逻辑管理形式，分别从会员信息存储、类别划分等视角，提升会员管理合理性。

票务管理程序中, 含有公共服务、票务处理功能、数据交互等程序, 同时关联于餐饮、娱乐等系统, 保障票务收 取的准确性，为游客在景区消费游玩奠定基础条件。在票务管理程序中，应增加安全防护技术，减少资金账目受到攻 击, 维护景区票务管理的安全性, 保障游客交易的平稳性。与此同时, 对于景区会员信息采取高级别的保密管理形式, 防止游客信息泄露问题，提升票务信息管理的智能性。

\section{3 结论}

综上所述, 在大数据技术背景下, 零盲区智慧旅游服务体系的构建, 涵盖了业务、服务、运维、财务、数据管理 各项模块, 以期提升游客数据的挖掘准确性, 尝试完善旅游服务体系, 增强智慧旅游运行能效, 助力旅游行业发展。 因此, 在后续智慧旅游项目运作期间, 应加强数据分析人才建设, 同时保障景区平台的运行平稳性, 以此最大化挖掘 客户在景区的消费需求, 获取较高的智慧旅游运作收益。

\section{[参考文献]}

[1]张成, 唐安业, 沈贵阳。大数据的全域智慧旅游云服务平台设计 $[\mathrm{J}]$. 科学与信息化, 2019 (32) : 36-37.

[2]施永贵,施永胜, 唐加福. 大数据时代智慧全域旅游云平台设计与研究 $[\mathrm{J}]$. 网络安全技术与应用, 2019(12): 143-145.

[3]张燕玲。焦作市全域智慧旅游精准云服务平台构建模式研究 [J]. 河南科技, 2019(16) : 21-23.

作者简介：何丞刚（1979.10-)，男，毕业院校：浙江大学，单位：杭州快盈信息科技有限公司，职务：CE0；方小明 (1980.1-), 男, 毕业院校: 西安电子科技大学, 单位: 杭州快盈信息科技有限公司, 职务: CT0; 冯庆锋 (1987. 3-), 男，毕业院校：杭州电子科技大学，单位：杭州快盈信息科技有限公司，职务：技术总监。 